\title{
PENGARUH KARAKTERISTIK PEKERJAAN, KOMPENSASI DAN GAYA KEPEMIMPINAN TERHADAP KEPUASAN KERJA KARYAWAN DEALER SEPEDA MOTOR DI PURBALINGGA
}

\author{
Titik Ardiati \\ Universitas Muhamamdiyah Purwokerto \\ Arini Hidayah \\ Universitas Muhamamdiyah Purwokerto
}

\begin{abstract}
ABSTRAK
Penelitian ini bertujuan untuk mengetahui pengaruh karakteristik pekerjaan, kompensasi dan gaya kepemimpinan terhadap kepuasan kerja karyawan dealer di Purbalingga baik secara parsial maupun simultan. Metode yang digunakan dalam pengambilan sampel adalah dengan cara sensus, yaitu pengambilan sampel yang dilakukan pada seluruh responden. Metode analisis yang digunakan adalah uji regresi linear berganda dengan tingkat signifikan $(\alpha)$ 0,05.Hasil penelitian ini menyimpulkan bahwa karakteristik pekerjaan dan gaya kepemimpinan secara parsial tidak berpengaruh terhadap kepuasan kerja karyawan, sedangkan kompensasi secara parsial berpengaruh terhadap kepuasan kerja karyawan. Karakteristik pekerjaan, kompensasi dan gaya kepemimpinan secara simultan berpengaruh terhadap kinerja.

Kata kunci : Karakteristik pekerjaan, kompensasi, gaya kepemimpinan dan kepuasan kerja.
\end{abstract}

\section{A. PENDAHULUAN \\ 1. Latar Belakang}

Sumber daya manusia merupakan salah satu sumber daya yang ada dalam suatu perusahaan organisasi disamping sumber daya yang lain, misalnya modal, material, mesin dalam perusahaan, sehingga menjadi bermanfaat dan tanpa adanya sumber daya manusia dan teknologi. Hal ini karena manusialah yang mengelolah sumber daya lainnya yang ada dalam perusahaan, sehingga dapat bermanfaat dan tanpa adanya sumber daya manusia maka sumber daya lainnya menjadi sangat penting. Hal yang penting diperhatikan dalam pemeliharaan hubungan tersebut antara lain adalah kepuasan kerja para karyawan.

Berkenaan dengan masalah kepuasan kerja karyawan tersebut, sebenarnya banyak faktor yang mempengaruhi ketidakpuasan karyawan dalam pekerjaannya diantaranya adalah sistem kompensasi yang dianggap tidak adil menurut persepsi karyawan, karena setiap pegawai akan selalu membandingkan antara rasio hasil dengan input dirinya terhadap rasio hasil dengan input orang lain. Perlakuan yang tidak sama baik dalam reward maupun punishment merupakan sumber kepuasan atau ketidakpuasan karyawan.

Dalam hal kesejahteraan karyawan, dealer Nusantara Motor, Anugerah Utama Motor dan Suzuki Isdiman telah melakukan berbagai upaya untuk meningkatkan kemakmuran karyawannya misalnya dengan memperhatikan kompetensi yang dimiliki karyawan, dan dengan menjalankan system rotasi dan mutasi yang baik antar bagian, dinas, department, maupun direktorat. Namun demikian, dalam kenyataannya masih timbul ketidakpuasan yang tercermin dari adanya demostrasi karyawan dengan salah satu tuntutannya adalah perbaikan sistem pengajaran. 
Faktor pengaruh lain yang perlu dipertimbangkan adalah konteks pekerjaan atau lingkungan pekerjaan seperti gaya kepemimpinan penyelia, hubungan dengan rekan kerja dan lain-lain.

Meskipun banyak faktor yang dapat mempengaruhi kepuasan kerja karyawan dalam suatu perusahaan, tetapi mengingat keterbatasan penulis untuk mengupas seluruh faktor penyebabnya maka setelah dilakukan studi awal kepada objek penelitian kepada Dealer Nusantara Motor, Anugerah Utama Motor, dan Suzuki Isdiman, penulis akan membatasi kepada tiga variabel bebas yaitu karakteristik pekerjaan, kompensasi dan gaya kepemimpinan.

\section{Perumusan Masalah}

a) Apakah terdapat pengaruh karakteristik pekerjaan secara parsial terhadap kepuasan kerja karyawan?

b) Apakah terdapat pengaruh kompensasi secara parsial terhadap kepuasan kerja karyawan?

c) Apakah terdapat pengaruh gaya kepemimpinan secara parsial terhadap kepuasan kerja karyawan?

d) Apakah terdapat pengaruh karakteristik pekerjaan, kompensasi, dan gaya kepemimpinan secara simultan terhadap kepusan kerja karyawan?

\section{Tujuan Penelitian}

1. Menganalisis pengaruh karakteristik pekerjaan secara parsial terhadap kepuasan kerja karyawan.

2. Menganalisis pengaruh kompensasi secara parsial terhadap kepuasan kerja karyawan.

3. Menganalisis pengaruh gaya kepemimpinan secara parsial terhadap kepuasan kerja karyawan.

4. Menganalisis pengaruh karakteristik pekerjaan, kompensasi dan gaya kepemimpinan secara simultan terhadap kepuasan kerja karyawan.

\section{B. TINJAUAN PUSTAKA}

\section{Karakteristik Pekerjaan}

Karakteristik pekerjaan merupakan faktor yang menunjukan ciri dari suatu jenis pekerjaan atau faktor yang membedakan antara satu pekerjaan dengan jenis pekerjaan lainnya. Karakteristik pekerjaan itu sendiri merupakan pengembangan dari job enrichment yang terdiri dari 3 (tiga) bagian, yaitu ;(Hackman dan Oldham, 1980).

a) Karakteristik pekerjaan inti.

b) Kondisi psikologis kritis (critical psychological state).

c) Hasil kerja individu.

Dalam Simamora (2004), teori model karakteristik pekerjaan (Job characteristics models) merupakan suatu pendekatan terhadap pemerkayaan pekerjan (job enrichment). Program pemerkayaan pekerjaan (job enrichment) berusaha merancang pekerjaan dengan cara membantu para pemangku jabatan memuaskan kebutuhan mereka akan pertumbuhan, pengakuan, dan tanggung jawab. Pemerkayaan pekerjaan menambahkan sumber kepuasan kepada pekerjaan. Metode ini meningkatkan tanggung jawab, otonomi, dan kendali. Penambahan elemen tersebut kepada pekerjaan kadangkala disebut pemuatan kerja secara vertikal (vertical job loading). Pemerkayaan pekerjaan (job enrichment) itu sendiri merupakan salah satu dari teknik desain pekerjaan.

Indikator karakteristik pekerjaan (Hackman dan Oldham, 1980) :

a) Variasi ketrampilan yang dibutuhkan (skill variety).

b) Prosedur dan kejelasan tugas (task identity).

c) Kepentingan tugas (task significant). 
d) Kewenangan dan tanggung jawab (autonomy).

\section{a. Kompensasi}

Dalam buku Malayu Hasibuan (2002) terdapat beberapa pengertian kompensasi dari beberapa tokoh yaitu :

1) Menurut Werther dan Davis kompensasi adalah apa yang seorang pekerja terima sebagai balasan dari pekerjaan yang diberikannya. Baik upah per jam ataupun gaji periodic didesain dan dikelola oleh bagian personalia.

2) Menurut Andrew F. Sikula kompensasi adalah segala sesuatu yang dikonstitusikan atau dianggap segai suatu balas jasa atau ekuivalen.

Menurut Garry Dessler (2000), mendefinisikan kompensasi sebagai bentuk pembayaran atau imbalan yang diberikan kepada karyawan oleh perusahaan sebagai atau balas jasa atas kontribusi mereka pada perusahaan.

Agar dalam pelaksanaannya program kompensasi dapat berjalan secara efektif, maka program kompensasi tersebut harus menerapkan azas-azas kompensasi (Hasibuan, 2001), yaitu:

a. Azas adil : artinya besarnya kompensasi yang diberikan kepada karyawan harus disesuaikan dengan prestasi kerja, jenis pekerjaan, resiko pekerjaan, tanggung jawab, jabatan pekerjaan dan memenuhi persyaratan internal konsisten.

b. Azas layak : artinya kompensasi yang diberikan pada karyawan harus dapat memenuhi kebutuhannya pada tingkat normative yang ideal.

Indikator kompensasi menurut Simamora :

a) Upah dan gaji.

b) Insentif.

c) Tunjangan.

d) Fasilitas.

\section{b. Gaya kepemimpinan}

Menurut Thoha (2003), mengartikan bahwa gaya kepemimpinan adalah suatu pola perilaku yang konsisten yang ditunjukkan dan sebagai yang diketahui oleh pihak lain ketika pimpinan berusaha mempengaruhi kegiatan-kegiatan orang lain.

Menurut Handoko (2009), terdapat dua gaya kepemimpinan yaitu 1). Gaya dengan orientasi tugas (task oriented), mengarahkan dan mengawasi bawahan secara tertutup untuk menjamin bahwa tugas dilaksanakan sesuai yang diinginkannya. Manajer dengan gaya kepemimpinan ini lebih memperhatikan pelaksanaan pekerjaan daripada pengembangan dan pertumbuhan karyawan. 2). Gaya kepemimpinan dengan berorientasi karyawan (employeeoriented), manajer berorientasi karyawan mencoba untuk lebih memotivasi bawahan dibanding mengawasi mereka. Mereka mendorong para anggota kelompok untuk berpartisipasi dalam pembangunan keputusan, menciptakan suasana persahabatan serta hubungan-hubungan saling mempercayai dan menghormati dengan para anggota kelompok.

Menurut Keith (1985), gaya kepemimpinan adalah pola tindakan pemimpin secara keseluruhan seperti yang dipersepsikan oleh para pegawainya, sedangkan menurut Bernadine (2002), mengemukakan bahwa gaya kepemimpinan merupakan cara yang digunakan pemimpin didalam mempengaruhi para pengikutnya.

Indikator gaya kepemimpinan menurut Ekvall\&Arvonen (1994) :

1. Pimpinan sangat jelas memberikan perintah.

2. Pimpinan selalu mengawasi pekerjaan bawahan.

3. Pimpinan membuat aturan dan prinsip kerja yang jelas.

4. Pimpinan memberikan nasehat atau solusi bagi penyelesaian pekerjaan. 
5. Pimpinan dapat menjadai kawan.

6. Pimpinan memberikan ide baru dan berbeda dalam hal pekerjaan.

7. Pimpinan mendorong pengembangan kamampuan bawahan.

\section{c. Kepuasan Kerja}

Kepuasan kerja merupakan suatu sikap umum terhadap pekerjaan seseorang, selisih antara banyaknya ganjaran yang diterima seorang pegawai dan banyaknya yang mereka yakini apa yang seharusnya mereka terima, (Robins, 2008). Menurut As 'ad (2000), mengemukakan kepuasan kerja adalah perasaan seseorang terhadap pekerjaannya. Dapat disimpulkan bahwa kepuasan kerja merupakan perasaan seseorang terhadap pekerjaannya yaitu keadaan emosi yang menyenangkan atau tidak menyenangkan dimana para karyawan memandang pekerjaan mereka dan mengetahui selisih antara banyaknya ganjaran yang diterima seorang pegawai dan banyaknya yang mereka yakini apa yang seharusnya mereka terima. yaitu:

Menurut Mangkunegara (2000) ada dua faktor yang mempengaruhi kepuasan kerja

1. Faktor karyawan, yaitu kecerdasan (IQ), kecakapan khusus, umur, jenis kelamin, kondisi fisik, pendidikan, pengalaman kerja, masa kerja, kepribadian, emosi, cara berpikir, persepsi dan sikap kerja.

2. Faktor pekerjaan, yaitu jenis pekerjaan, struktur organisasi, pangkat (golongan), kedudukan, mutu pengawasan, jaminan finansial, kesempatan promosi jabatan, interaksi sosial, dan hubungan kerja.

Indikator pengukuran kepuasan kerja menurut penelitian dari Spector dalam (Yuwono, 2005) :

1. Upah : jumlah dan rasa keadilannya.

2. Promosi : peluang dan rasa keadilan untuk mendapatkan promosi.

3. Supervise : keadilan dan kompetensi penugasan manajerial oleh penyelia.

4. Benefit : asuransi, liburan dan bentuk fasilitas lainnya.

5. Contingent rewards : rasa hormat, diakui dan diberikan apresiasi.

6. Operating procedures : kebijakan, prosedur dan aturan.

7. Cowokers : rekan kerja yang menyenangkan dan kompeten.

8. Nature Of Work: tugas itu sendiri dapat dinikmati atau tidak.

9. Communication : berbagai informasi didalam organisasi (verbal maupun non verbal).

\section{METODOLOGI PENELITIAN}

Rancangan penelitian yang dilakukan adalah penelitian kausalitas, dimana penelitian dilakukan untuk mengetahui pengaruh karakteristik pekerjaan yang ditetapkan, kompensasi yang diberikan perusahaan dan gaya kepemimpinan yang diterapkan dalam perusahaan terhadap tingkat kepuasan kerja karyawan Dealer Sepeda Motor di Purbalingga, sedangkan metode penelitian yang dilakukan adalah metode survey.

Jumlah sampel penelitian adalah sebanyak 87 responden karyawan dealer Nusantara Motor, Anugerah Utama motor dan Suzuki Isdiman Purbalingga. Tekhnik pengambilan sampel dengan cara sensus, karena jumlah semua populasi yang berjumlah 87 akan dijadikan sampel.

Instrumen pengumpulan data yang digunakan dalam penelitian ini adalah kuesioner yang berisi butiran-butiran pertanyaan yang berkaitan dengan indikator-indikator yang ada pada variabel-variabel.

Data yang digunakan dalam penelitian sebagaian besar adalah data primer serta beberapa data sejunder. Data primer yang merupakan data utama yang akan digunakan untuk 
analisis, diperoleh langsung dengan menyebarkan kuesioner untuk diisi oleh responden yang dituju (target subject), sedangkan data sukender lainnya yang ada di Dealer Nusantara Motor, Anugerah Utama Motor dan Suzuki Isdiman.

Untuk mengetahui ada tidaknya hubungan antara variabel dependen dengan variabel independen baik secara parsial maupun simultan, maka digunakan metode analisis ststistik, yaitu tekhnik analisis regresi linier berganda serta uji F dan t. Adapun model matematika dari regresi ini adalah sebagai berikut :

$$
\begin{aligned}
& \mathrm{Y}=\mathrm{a}+\mathrm{b}_{1} \mathrm{X}_{1}+\mathrm{b}_{2} \mathrm{X}_{2}+\mathrm{b}_{3} \mathrm{X}_{3}+\mathrm{e} \\
& \text { Dimana } \\
& \mathrm{Y} \quad: \text { Kepuasan Kerja } \\
& \mathrm{a} \quad: \text { Konstanta } \\
& \mathrm{b}_{1} \mathrm{~b}_{2} \mathrm{~b}_{3}: \text { Koefisien Regresi } \\
& \mathrm{X}_{1} \quad \text { : Karakteristik Pekerjaan } \\
& \mathrm{X}_{2} \quad \text { : Kompensasi } \\
& \mathrm{X}_{3} \quad \text { : Gaya Kepemimpinan } \\
& \mathrm{e} \quad: \text { Variabel Gangguan }
\end{aligned}
$$

\section{ANALISIS DATA DAN PEMBAHASAN}

\section{Uji Reliabilitas dan Validitas}

Data yang diperoleh telah terlebih dahulu diuji dengan uji Reliabilitas dan Validitas. Hasil pengujian data-data tersebut memperhatikan bahwa kesempatan penelitian adalah valid dan reliabel seperti disajikan pada tabel berikut :

Tabel 1. Hasil Uji Reliabilitas

\begin{tabular}{|l|c|l|}
\hline \multicolumn{1}{|c|}{ Variabel } & Hasil Pengukuran (x) & Keterangan \\
\hline Kepuasan Kerja & 0,710 & Reliabel \\
\hline Karakteristik pekerjaan & 0,531 & Reliabel \\
\hline Kompensasi & 0,710 & Reliabel \\
\hline Gaya Kepemimpinan & 0,433 & Reliabel \\
\hline
\end{tabular}

Tabel 2. Hasil Uji Validitas

\begin{tabular}{|c|c|c|c|}
\hline \multicolumn{4}{|c|}{ Variabel Kepuasan Kerja } \\
\hline No & Kode Variabel & $\begin{array}{c}\text { Hasil } \\
\text { Pengukuran }\end{array}$ & Validitas \\
\hline 1 & KK1 & 0,000 & Valid \\
\hline 2 & KK2 & 0,000 & Valid \\
\hline 3 & KK3 & 0,000 & Valid \\
\hline 4 & KK4 & 0,000 & Valid \\
\hline 5 & KK5 & 0,000 & Valid \\
\hline 6 & KK6 & 0,000 & Valid \\
\hline 7 & KK7 & 0,001 & Valid \\
\hline 8 & KK8 & 0,000 & Valid \\
\hline 9 & KK9 & 0,000 & Valid \\
\hline 10 & KK10 & 0,000 & Valid \\
\hline \multicolumn{3}{|c|}{ Variabel Karakteristik Pekerjaan } \\
\hline
\end{tabular}




\begin{tabular}{|c|c|c|c|}
\hline 1 & KP1 & 0,000 & Valid \\
\hline 2 & KP2 & 0,000 & Valid \\
\hline 3 & KP3 & 0,000 & Valid \\
\hline 4 & KP4 & 0,000 & Valid \\
\hline 5 & KP5 & 0,002 & Valid \\
\hline 6 & KP6 & 000 & Valid \\
\hline \multicolumn{4}{|c|}{ Variabel Kompensasi } \\
\hline 1 & KM1 & 0,000 & Valid \\
\hline 2 & KM2 & 0,000 & Valid \\
\hline 3 & KM3 & 0,000 & Valid \\
\hline 4 & KM4 & 0,000 & Valid \\
\hline 5 & KM5 & 0,000 & Valid \\
\hline 6 & KM6 & 0,000 & Valid \\
\hline Variabel Gaya Kepemimpinan & 0,000 & Valid \\
\hline 1 & GP1 & 0,000 & Valid \\
\hline 2 & GP2 & 0,000 & Valid \\
\hline 3 & GP3 & 0,001 & Valid \\
\hline 4 & GP4 & 0,000 & Valid \\
\hline 5 & GP5 & 0,000 & Valid \\
\hline 6 & GP6
\end{tabular}

2. Uji regresi Linier Berganda antara Variabel -Variabel dalam Karakteristik Pekerjaan, Kompensasi dan Gaya Kepemimpinan Terhadap Kepuasan Kerja.

Data yang diperoleh dari 86 responden yang telah mengisi kuesioner secara lengkap, selanjutnya dianalisis dengan hasil pada tabel 4.3 berikut ini :

Tabel 4.3. Hasil uji regresi linier berganda antara variabel-variabel dalam karakteristik pekerjaan, kompensasi dan variabel-variabel dalam gaya kepemimpinan terhadap kepuasan kerja.

\begin{tabular}{|c|c|c|c|c|c|}
\hline Variabel & B & Std. Error & Beta & t hitung & $\mathrm{P}$ \\
\hline Konstanta & 22.666 & 4.568 & & 4.962 & 0.000 \\
$\mathrm{X}_{1}$ & -0.135 & 0.181 & -0.071 & -0.747 & 0.457 \\
$\mathrm{X}_{2}$ & 0.607 & 0.111 & 0.523 & 5.471 & 0.000 \\
$\mathrm{X}_{3}$ & 0.263 & 0.132 & 0.193 & 1.990 & 0.050 \\
\hline
\end{tabular}

Tabel 4.4. Hasil uji Adjusted $\mathbf{R}^{2}$

\begin{tabular}{|l|l|l|c|c|}
\hline Model & $\mathrm{R}$ & R Square & $\begin{array}{c}\text { Adjusted R } \\
\text { Square }\end{array}$ & $\begin{array}{c}\text { Std. Error of the } \\
\text { Estimate }\end{array}$ \\
\hline
\end{tabular}




\begin{tabular}{|l|l|r|r|r|}
\hline 1 & $.620^{\mathrm{a}}$ & .384 & .361 & 3.185 \\
\hline
\end{tabular}

Persamaan regresi untuk mengestimasi variabel terikat dengan menggunakan seluruh variabel bebas adalah sebagai berikut :

$$
Y=22,666+-0,071 X_{1}+0,523 X_{2}+0,193 X_{3}+e
$$

Keterangan :

$$
\begin{array}{ll}
\mathrm{Y} & : \text { Kepuasan Kerja } \\
\mathrm{X}_{1} & : \text { Karakteristik Pekerjaan } \\
\mathrm{X}_{2} & : \text { Kompensasi } \\
\mathrm{X}_{3} & \text { : Gaya Kepemimpinan } \\
\mathrm{E} & : \text { Error }
\end{array}
$$

Berdasarkan tabel 4.3, terlihat bahwa nilai $\mathrm{p}$ (Sig.) $\mathrm{X}_{1}=0.457$ secara parsial variabel karakteristik pekerjaan tidak berpengaruh positif terhadap kepuasan kerja karyawan dengan demikian hipotesis pertama ditolak, sedangkan nilai Sig. $\mathrm{X}_{2}=0.000$ secara parsial variabel kompensasi berpengaruh positif terhadap kepuasan kerja karyawan, dengan demikian hipotesis kedua diterima, dan nilai Sig. $\mathrm{X}_{3}=0.050$ yang berarti secara parsial bahwa variabel gaya kepemimpinan tidak berpengaruh positif terhadap kepuasan kerja karyawan, dengan demikian hipotesis ketiga ditolak.

Variabel independen secara simultan berdasarkan tabel 4.3, terlihat bahwa nilai $\mathrm{p}($ sig. F $)=0.000<0.05$, maka ini berarti bahwa berdasarkan hasil penelitian karakteristik pekerjaan, kompensasi dan gaya kepemimpinan secara simultan mempunyai pengaruh yang signifikan terhadap kepuasan kerja karyawan dengan demikian hipotesis keempat diterima.

Variasi perubahan nilai variabel dependen $(\mathrm{Y})$ yang dapat dijelaskan oleh seluruh variabel independen secara simultan sebesar $36.1 \%$ dan sisanya $63.9 \%$ dipengaruhi oleh variabel lain yang tidak diteliti dalam penelitian ini.

\section{E. KESIMPULAN DAN SARAN}

\section{Kesimpulan} lain:

Berdasarkan analisis yang telah dilakukan, maka ditarik beberapa kesimpulan, antara

a. Hipotesis pertama yang menyatakan bahwa karakteristik pekerjaan, tidak berpengaruh signifikan secara parsial terhadap kepuasan kerja karyawan, Ha ditolak. Hal ini ditunjukkan dengan nilai signifikansi variabel sebesar 0,457.

b. Hipotesis kedua yang menyatakan bahwa kompensasi berpengaruh signifikan secara parsial terhadap kepuasan kerja karyawan, Ha diterima hal ini ditunjukkan dengan nilai signifikan variabel sebesar 0,000 .

c. Hipotesis ketiga yang menyatakan bahwa gaya kepemimpinan tidak berpengaruh signifikan secara parsial terhadap kepuasan kerja karyawan, Ha ditolak hal ini ditunjukkan dengan nilai signifikansi variabel sebesar 0,05 .

d. Hipotesis keempat yang menyatakan bahwa karakteristik pekerjaan, kompensasi dan gaya kepemimpinan berpengaruh signifikan secara simultan terhadap kepuasan kerja karyawan, Ha diterima. Hal ini ditunjukkan dengan nilai signifikansi uji $F$ sebesar 0,000 kurang dari 
0,05 , namun nilai adjusted $\mathrm{R}^{2}$ sebesar $36,1 \%$, yang berarti $63,9 \%$ penelitian ini dipengaruhi oleh faktor lain yang tidak diteliti dalam penelitian ini.

e. Berdasarkan hasil penelitian ini yang bertujuan untuk meningkatkan R Square, ternyata peneliti belum berhasil, sebab R Square yang dihasilkan ternyata menurun.

\section{Saran}

a. Untuk meningkatkan kepuasaan kerja karyawan diketiga dealer yaitu Nusantara Motor, Anugrah Utama Motor dan Suzuki Isdiman, pimpinan perlu memperhatikan:

1) Karakteristik pekerjaan, pimpinan harus tetap mempertahankan karyawannya untuk bekerja sesuai dengan keahliannya atau jenis pekerjaannya.

2) Kompensasi, sebaiknya pimpinan harus memperhatikan lagi cara pemberian kompensasi, khususnya karyawan yang berprestasi untuk diberi penghargaan, dan secara adil semua karyawan diberikan fasilitas yang dibutuhkan oleh karyawan tersebut.

3) Gaya kepemimpinan, pimpinan harus tetap mempertahankan sikap yang profesional dalam memberikan arahannya terhadap karyawannya.

b. Bagi penelitian lanjutan, perlu menambah variabel seperti motivasi kerja, kinerja karyawan, kedisiplinan.

\section{DAFTAR PUSTAKA}

As'ad, Moh. 2000. Psikologi Industri, Seri Ilmu Sumber Daya Manusia. Liberty : Yogyakarta.

Bernadine. 2002. Dasar-dasar Kepemimpinan dan Pengembangannya. ANDI. Yogyakarta.

Davis, Keith and Jhon Newstrom. (1985). Human Behaviour at Work : Organizational Behaviour. Mc. Graw. Hill Inc. new York.

Dessler, G. (2000). Human Resource Management. Eight Edition, Prentice Hall International Inc., USA.

Ekvall\&Arvonen. 1994. Pasca Sarjana Magister Sains dan Dokter Ilmu Ekonomi $U G M$; Yogyakarta.

Mangkunegara, A. P. 2000. Manajemen Sumber Daya Manusia. Cetakan Pertama, Rosda, Bandung.

Mondy, R. W. Neo, R. M. (1993). Human Resource Management. Sixth Edition, Allyn \& Bacon Inc, USA.

Hackman dan Oldham, (1980).http://kepemimpinan-karakteristik-pekerjaan-dankepuasan-kerja/.

Handoko. 2009. Manajemen edisi 2. BPFE Yogyakarta

Hasibuan. 2001. Manajemen Sumber Daya Manusia. Bumi Aksara : Jakarta.

Hasibuan. 2002. Manajemen Sumber Daya Manusia. Bumi Aksara : Jakarta. 
Robbins, Stephen. 2008. Prilaku organisasi, Edisi 1\&2 Salemba Empat : Jakarta.

Simamora 2004: 129.http://jurnal-sdm.blogspot.com/2007/12/model-karakteristikpekerjaan-job.html.tg129/06/2012.

Thoha. 2003. Kepemimpinan Dalam Manajemen. Raja Grafindo Persada. Yogyakarta.

Yuwono.2005(http//jurnal-sdm.blogspot.com/2009/09/indikator-untuk-mengukurkepuasan-kerja.html) 